\title{
UNIVERSIDADE
}

\author{
REITOR \\ Prof. Felipe Martins Müller \\ Vice-Reitor: Prof. Dalvan José Reinert \\ CENTRO DE CIÊNCIAS SOCIAIS E HUMANAS - CCSH \\ DIRETOR \\ Rogério Ferrer Koff \\ Vice Diretor: Mauri Leodir Löbler \\ DEPARTAMENTO DE CIÊNCIAS ECONÔMICAS \\ CHEFE \\ Uacauan Bonilha \\ Subchefe: Adriano José Pereira
}

\section{CORPO EDITORIAL}

\section{EDITOR RESPONSÁVEL}

José Renato Ferraz da Silveira

\section{EDITORES}

Cristina Farias, Daniel do Nascimento Paim, Fernanda Maschio, Guilherme da Cruz Backes, Juliana Graffunder Barbosa, Leonardo Augusto Peres, Lia Fernanda da Rosa e Thales da Silva Carvalho.

\section{CONSELHO EDITORIAL}

Adayr da Silva Ilha (UFSM), Adriano José Pereira (UFSM), Gláucia Campregher (UFGRS), José Carlos Martines Belieiro Junior (UFSM), José Luiz de Moura Filho (UFSM), José Renato Ferraz da Silveira (UFSM), Marcelo Arend (UFSC), Paulo Gilberto Fagundes Vizentini (UFRGS), Ricardo Seitenfus (UFSM), Rita Inês Paetzhold Pauli (UFSM), Sérgio Alfredo Massen Prieb (UFSM), Uacauan Bonilha (UFSM)

\footnotetext{
Nota: Os trabalhos assinados exprimem conceitos da responsabilidade de seus autores, coincidentes ou não com os pontos de vista da redação da Revista.

Todos os direitos Reservados: Proibida a reprodução total ou parcial, sem a prévia autorização do Núcleo, por qualquer meio ou processo, especialmente por sistemas gráficos, microfímicos, fotográficos ou videográficos. Vedada a memorização e/ou recuperação total ou parcial, bem como a inclusão de quaisquer partes desta obra em qualquer sistema de processamento de dados. Essas proibições aplicam-se também às características da obra e à sua editoração. A violação dos direitos autorais é punível como crime (art. 184 e $\S \S$, do Código Penas, cf Lei ${ }^{0} 6.895$, de 17-12-1980) com pena de prisão e multa, conjuntamente com busca e apreenção e indenizações diversas (arts. 122, 123, 124 e 126, da Lei n ${ }^{0}$ 5.988 de 14-12-1973, Lei dos Direitos Autorais).
} 


\section{PARECERISTAS}

Alfredo Gugliano (UFRGS)

Doutorado em Ciencias Políticas y Sociología

(Universidad Complutense de Madrid)

alfredogugliano@uol.com.br

Álvaro Augusto de Borba Barreto (UFPEL)

Doutorado em História (PUC-RS)

albarret.sul@terra.com.br

André Luiz Reis da Silva (UFRGS)

Doutorado em Relações Internacionais

reisdasilva@hotmail.com

Antônio Carlos Lessa (UnB)

Doutorado em História das Relações

Internacionais (UnB)

alessa@unb.br

Antônio Manoel Elibio Júnior (UFSC)

Doutorado em História Social Política (Unicamp)

e pós-doutorando em Ciência Política e Relações

Internacionais (UFP)

tonyelibi@@hotmail.com

Ceres Karan Brum (UFSM)

Doutorado em Antropologia

cereskb@terra.com.br

Danilo da Cás (IESB)

Doutorado em Pedagogia (Universidade Estadual

Paulista - Marília) e Doutorado em Pedagogia (USC)

danidacas@uol.com.br

danilodacas@uol.com.br

danilodacas@zipmail.com.br

Diorge Alceno Konrad (UFSM)

Doutorado em História Social

diorgekonrad@bol.com.br
Fernando da Silva Camargo (UFPEL)

Doutorado em História (PUC-RS)

fscam@hotmail.com

camargo@clio.pro.br

Graciela De Conti Pagliari (UFSC)

Doutorado em Relações Internacionais (UnB)

graciela.pagliari@gmail.com

Jerônimo Siqueira Tybusch (UFSM)

Doutorado em Direito

jeronimotybusch@cead.ufsm.br

Léo Rodriguez Peixoto (UFPEL)

Doutorado em Sociologia (UFRGS)

leo.peixotto@gmail.com

Mônica Salomón (UFSC)

Doutorado em Ciência Política (Universidad Autónoma

de Barcelona)

monicasalomon@cse.ufsc.br

Norma Breda dos Santos (UnB)

Doutorado em História e Política Internacional (Institut

Universitaire de Hautes Études Internationales - Suiça) breda@unb.br

Reginaldo Teixeira Perez (UFSM)

Doutorado em Ciência Política (Instituto Universitário de

Pesquisas do Rio de Janeiro)

rtpp10@hotmail.com

Sebastião Peres (UFPEL)

Doutorado em Educação (UFMG)

sebasper@terra.com.br

Thiago Rodrigues (UFF)

Doutorado em Relações Internacionais

th.rodrigues@gmail.com 